\title{
INFLUENCE OF THE EARTHQUAKE DIRECTION ON SEISMIC RESPONSE OF PLAN IRREGULAR RC FRAME BUILDINGS
}

\begin{abstract}
Nonlinear response of structures is usually evaluated considering two accelerograms acting simultaneously along orthogonal directions. In this paper the influence of the earthquake direction on the seismic response of buildings structures is examined. Three multi-story RC buildings, representing a very common structural typology in Italy, are assumed in the paper as case-studies for the evaluation. They are respectively a rectangular plan shape, a L plan shape and a rectangular plan shape with courtyard buildings. Nonlinear static and dynamic analyses are performed considering different seismic levels, characterized by a peak ground acceleration on stiff soil equal to $0.35 \mathrm{~g}, 0.25 \mathrm{~g}$ and $0.15 \mathrm{~g}$.

Nonlinear dynamic analyses are carried out considering twelve different earthquake directions, rotating the direction of both the orthogonal components by $30^{\circ}$ for each analysis (from $0^{\circ}$ to $330^{\circ}$ ). The survey is carried out on the L plan shape structure. The results show that the angle of the seismic input motion significantly influences the response of RC structures: the critical seismic angle, i.e. the incidence angle that produces the maximum demand, provides an increase up to $37 \%$ both in roof displacements and in terms of plastic hinge rotations.
\end{abstract}

\section{KEYWORDS}

Plan irregularity, nonlinear analyses, reinforced concrete buildings, seismic performance, ground motion directionality. 


\section{INTRODUCTION}

Irregular structures show an unfavourable seismic behaviour, characterized by the concentration of plastic demand in a limited portion of the structure; this issue can cause early collapse under strong seismic motion. All modern building codes provide rules to verify the regularity of structures either in plan or in elevation; in case the rules are not followed, some "penalties" in the design are provided (CEN, 2004). The evidence of past earthquakes clearly denoted that the irregularity in plan, which can be caused by asymmetric distributions of mass, stiffness and strength, is one of the most frequent sources of severe damage, since it causes torsional floor rotations localizing the seismic demand in small portions of the building (e.g., De Stefano and Pintucchi, 2008). In past years, large research efforts were devoted to the study of the seismic response of irregular structures, both in plan (e.g., Athanatopoulou et al., 2006, Roy and Chakroborty, 2013) and in elevation (e.g., Magliulo et al., 2012a). The presence of nonstructural components, such as infill systems, strongly influences the lateral stiffness of the portion of the structure in which they are inserted (Magliulo et al., 2012c, Magliulo et al., 2013) and they may also affect the regularity of the structural system.

The modern seismic codes, as Eurocode 8 (CEN, 2004), allow using different analysis methodologies: 1) lateral force, 2) modal response spectrum, 3) static nonlinear and 4) dynamic nonlinear analyses. Their level of reliability decreases from 4) to 1) and, consequently, the safety margin with respect to the same limit state should increase according to the same order (Magliulo et al., 2007). The choice of a method depends on the structural characteristics (regularity, fundamental periods, presence of isolation systems) and the importance of the structure. Certainly, among the different approaches, nonlinear dynamic analysis is able to provide the best prediction of the structural response. The influence of the seismic analysis on the vulnerability assessment of buildings is also discussed in Magliulo et al. (2008) focusing on existing precast industrial buildings.

The nonlinear response of 3D structures is usually determined considering the two horizontal seismic components acting simultaneously (e.g., Di Sarno et al., 2011, Magliulo and Ramasco, 2007), that simulate the realistic condition to which a building is subjected during a seismic event. Many years ago, MacRae and Mattheis (2000) concluded that the assessment of building drifts for bidirectional shaking effects is dependent on the chosen reference axes. Athanatopoulou (2005) proposed analytical formulas for the determination of the critical angle of seismic incidence, i.e. the incidence angle of the seismic input that produces the maximum demand, and the corresponding maximum value of a response quantity of structures considering either two or three seismic components. The developed analytical formulas are derived assuming that the structure behaves linearly. Rigato and Medina (2007) demonstrated that the inelastic peak deformation demands are underestimated if bi-directional ground motions are applied only along the principal axes of an inelastic building when compared to those obtained at other angles of incidence. proposed a procedure that takes into account the critical seismic angle and they demonstrated that this procedure is the most efficient for the design of RC frame elements. (Reyes and Kalkan, 2012) examined the influence that the angle of incidence of the ground motion has on several engineering demand parameters (EDPs). The study focused on both symmetric and asymmetric buildings in near fault sites, in which the records are typically rotated to fault-normal/fault-parallel directions. It was found that nonlinear dynamic analyses for ground motions oriented in the FN/FP axes could underestimate the peak value of mediandisplacement overall orientations. Such an underestimation was less than $20 \%$ in case a large set of ground motions was adopted.

The aim of the study presented here is to analyse the seismic behaviour of three Italian typical RC buildings, both regular and irregular in plan, with different nonlinear analysis methods, in order to evaluate the differences, if any, among the analysis methodologies. In particular, the results of nonlinear dynamic analysis, nonlinear static analysis with "modal" load pattern and nonlinear static analysis with "uniform" load pattern are compared. Furthermore, the influence of the incidence angle of the seismic action is also investigated by performing twelve nonlinear dynamic analyses, rotating the direction of both the orthogonal components by $30^{\circ}$ for each analysis (from $0^{\circ}$ to $330^{\circ}$ ).

The analyses are performed both at the Significant Damage Limit State, assuming as reference the EC8 elastic spectrum characterised by a return period of 475 years, corresponding to a $10 \%$ probability of exceedance in 50 years, and at the Near Collapse Limit State, characterised by a return period of 2475 years, assuming as reference the same spectrum amplified by a factor equal to 1.5 (Ordinanza del Presidente del Consiglio dei Ministri n. 3274 del 20/3/2003, 2003).

The results of the nonlinear analysis methodologies are compared in terms of the ratio between the required rotation and the capacity at the top and at the bottom of each column in the two directions and in terms of roof displacements. Some observations on the influence of the incidence angle of the seismic action are also made; they aim at the evaluation of a critical angle for which the seismic demand attains the maximum values. 


\section{METHODOLOGY}

In this study three different RC buildings are considered, whose geometry is reported in Figure 1. The selected buildings are representative of Italian typical RC structures, both regular (building no. 1) and irregular in plan (buildings no.no. 2 and 3). The chosen geometry and longitudinal and horizontal reinforcement are commonly found in the Italian territory.

The building no. 1 (Figure 1a) is a "regular" doubly symmetric four-storey building with $3.20 \mathrm{~m}$ interstorey height for each level; the dimensions of the sections of all the columns and beams, expressed in $\mathrm{cm}$, are $30 \times 60$. Concrete average cubic strength, equal to $33.5 \mathrm{~N} / \mathrm{mm}^{2}$, and steel average strength, equal to $500 \mathrm{~N} / \mathrm{mm}^{2}$, are adopted.

The building no. 2 (Figure 1b) is a L plan shape five-storey structure with an interstorey height equal to $3.50 \mathrm{~m}$ for each level. The dimensions of the columns sections remain constant for the whole height of the building and they are represented by three different typologies: $40 \times 40,40 \times 50,40 \times 70$. Also the beams have different section dimensions: $40 \times 60,40 \times 50,25 \times 50$. Concerning the materials, concrete average cubic strength, equal to $25 \mathrm{~N} / \mathrm{mm}^{2}$, and steel average strength, equal to $400 \mathrm{~N} / \mathrm{mm}^{2}$, are adopted.

The building no. 3 (Figure 1c) has a rectangular shape with a central courtyard; it is a five-storey building, with the interstorey height equal to $3.50 \mathrm{~m}$ for each level. The columns have two different typologies of section dimensions maintained constant for all the storeys: $40 \times 55$ and $40 \times 70$. Also the beams have different section dimensions assembled in three typologies: $40 \times 60,40 \times 50,25 \times 40$. As for building no. 2 , concrete average cubic strength, equal to $25 \mathrm{~N} / \mathrm{mm}^{2}$, and steel average strength, equal to $400 \mathrm{~N} / \mathrm{mm}^{2}$, are used.

The structures were defined and selected by a wide research group, in the framework of the ReLUIS-DPC 20052008 project, in order to be representative of the current Italian RC building stock. Further details on the geometry of the elements are included in Bianchi et al. (2007) and in Maddaloni et al. (2008).

The buildings are assumed to be founded on a "B" soil type, according to EC8 classification, i.e. soil with an average shear wave velocity in the range $360 \mathrm{~m} / \mathrm{s}$ and $800 \mathrm{~m} / \mathrm{s}$.

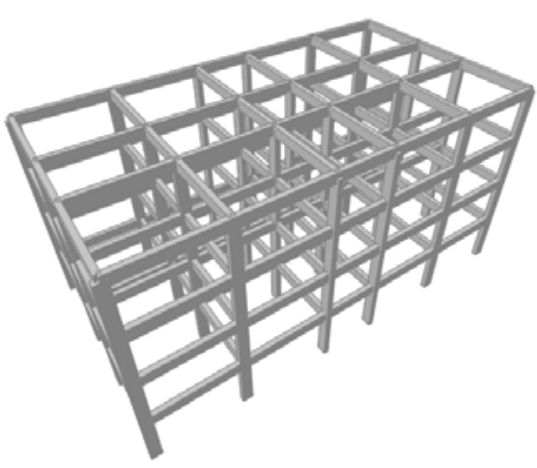

(a)

$\mathrm{T}_{1}=0.738 \mathrm{~s} ; \mathrm{T}_{2}=0.720 \mathrm{~s} ; \mathrm{T}_{3}=0.616 \mathrm{~s}$

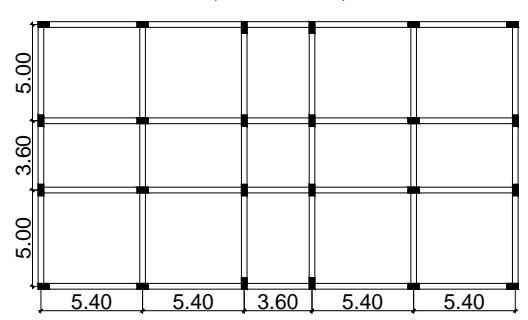

(d)

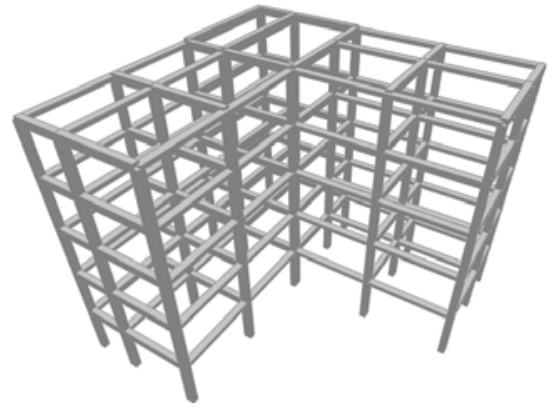

(b)

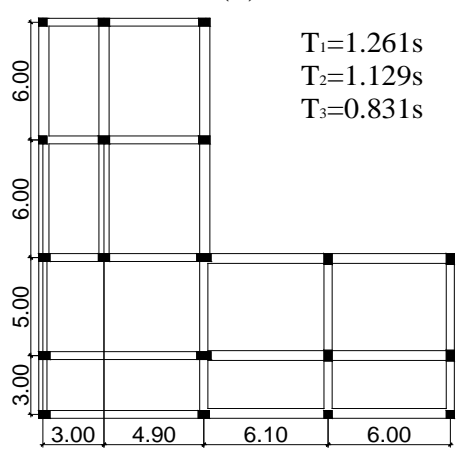

(e)

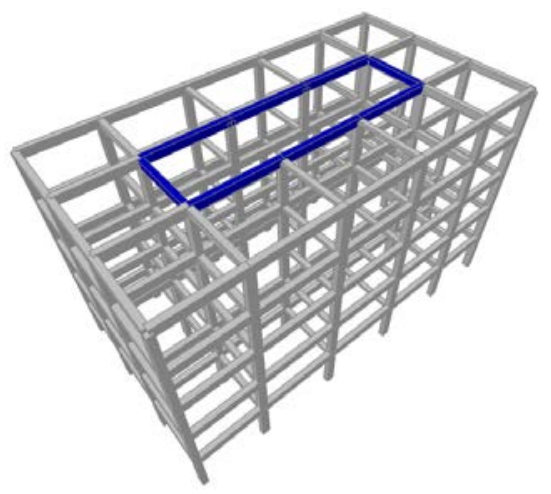

(c)

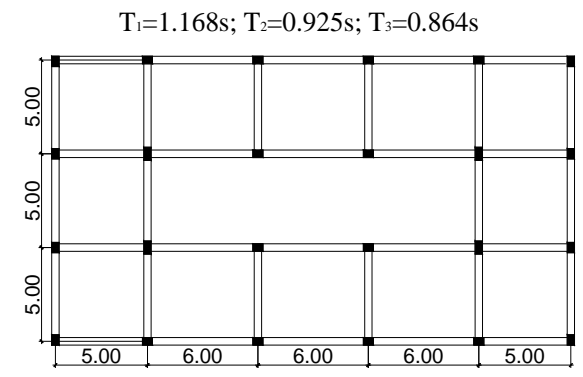

(f)

Figure 1. 3D view of the analysed buildings: (a) building n. 1; (b) building n. 2; (c) building n. 3. Plan view of the considered buildings and the first three natural periods: (d) building no. 1; (e) building no. 2; (f) building no. 3.

Modal analyses of the structures are performed considering a reduction of the $50 \%$ in the inertia moment of the section of all the elements, according to the prescriptions included in Eurocode 8 (CEN, 2004); Eurocode 8 allows reducing the flexural stiffness properties of concrete elements up to one-half of the corresponding stiffness of the uncracked elements, in order to take into account the effect of cracking. Building no. 1 and building no. 3 are characterised by a first translational mode along the smallest plan dimension direction, with period equal to $0.74 \mathrm{~s}$ and $1.16 \mathrm{~s}$, respectively. Building no. 2 is characterised by a first torsional mode, with a period equal to $1.26 \mathrm{~s}$. 
Nonlinear analyses are performed by means of two computer programs, i.e. SAP2000 (CSI Computer \& Structures Inc., 2004) and CANNY99 (Li, 1996). Both beams and columns are characterised by lumped plasticity models. For the columns two independent nonlinear springs are assigned, one for each orthogonal direction. No axial force-bending moment interaction is considered in the plastic hinges. Bending moment springs are characterised by a bilinear skeleton curve, defined by the yielding and ultimate moment and the corresponding rotations. Yielding and ultimate moments are defined by the bilinear envelope of the moment-curvature diagram using the MC program $(\mathrm{Li}, 1996)$. The yielding $\theta_{y}$ and the ultimate rotations $\theta_{u}$ of the plastic hinges are evaluated as provided by EC8 (CEN, 2005). The hysteretic model is Takeda type; also the pinching effect is taken into account.

The moments and the corresponding curvatures are computed considering a parabola-rectangle diagram for concrete under compression, with a strain value at the end of the parabola equal to $0.2 \%$ and an ultimate strain equal to $0.35 \%$. An elastic-perfectly plastic steel stress-strain diagram is considered for the ribbed longitudinal bars. Bond-slip relationship is not directly taken into account. The above mentioned mean strength values are assigned to concrete $\left(f_{c}\right)$ and steel $\left(f_{y}\right)$ strength.

\section{NONLINEAR ANALYSES}

For each building, pushover analyses are performed in both the horizontal directions according to the N2 method (Fajfar, 2000). Two different distributions of horizontal forces are considered: a "uniform" pattern, based on lateral forces that are proportional to mass and a "modal" pattern, consistent with the lateral force distribution of the first mode. Furthermore, the analyses consider three different seismic levels, i.e. the demand is represented by three elastic spectra obtained considering three values of design peak ground accelerations on stiff soil: $0.15 \mathrm{~g}$, $0.25 \mathrm{~g}$ and $0.35 \mathrm{~g}$. The structure is verified for the different limit states (Significant Damage Limit State and Near Collapse Limit State) and the three seismic intensities.

Both the horizontal components of three sets of 7 earthquakes, i.e. 42 natural recorded events, are used for nonlinear dynamic analyses whose results are shown herein. The three sets are selected according to the EC8 rules from the European Strong motion Database (Figure 2) (Ambraseys et al., 2002). Arbitrary accelerogram magnitude and distance bins are considered in the preliminary search. They are selected in order to be compatible (i.e., Iervolino et al., 2008) with the EC8 elastic spectrum for a design ground acceleration on stiff soil equal to $0.35 \mathrm{~g}, 0.25 \mathrm{~g}$ and $0.15 \mathrm{~g}$ (thick black line in Figure 2). A 1.2 scale factor is applied to three accelerograms in the set that matches the spectrum with a design ground acceleration equal to $0.35 \mathrm{~g}$. According to the selection procedures presented in literature (Iervolino et al., 2008, Iervolino et al., 2010, Maddaloni et al., 2012), they satisfy the EC8 rule for spectrum matching: in the range of periods between $0.2 T_{1}$ and $2 T_{1}$, where $T_{1}$ is the fundamental period of the structure, the mean 5\% damping elastic spectrum (thick red line in Figure 2) of the selected accelerograms, is not less than $90 \%$ of the corresponding value of the $5 \%$ damping elastic response spectrum (black line in Figure 2). Then, nonlinear dynamic analyses, considering different hazard levels, i.e. $a_{g}=0.15 \mathrm{~g}, a_{g}=0.25 \mathrm{~g}, a_{g}=0.35 \mathrm{~g}$, for the Significant Damage Limit State are performed. The main characteristics of the selected earthquakes are listed in Tables 1, 2 and 3. Instead, for the Near Collapse Limit State, characterised by a return period of 2475 years, the above mentioned analyses are repeated with the same earthquakes amplified by a factor equal to 1.5 according to OPCM 3274 (Ordinanza del Presidente del Consiglio dei Ministri n. 3274 del 20/3/2003, 2003).

\begin{tabular}{|c|c|c|c|c|c|c|c|}
\hline Earthquake code & Earthquake name & Moment magnitude & Epicentral Distance [km] & Date [dd/mm/yy] & PGA_X [g] & PGA_Y [g] & SF [-] \\
\hline 000187 & Tabas & 7.3 & 57 & $16 / 09 / 1978$ & 0.93 & 1.10 & 1.0 \\
\hline 000196 & Montenegro & 6.9 & 25 & $15 / 04 / 1979$ & 0.45 & 0.31 & 1.0 \\
\hline 000230 & Montenegro (aftershock) & 6.2 & 8 & 24/05/1979 & 0.12 & 0.27 & 1.2 \\
\hline 000291 & Campano Lucano & 6.9 & 16 & 23/11/1980 & 0.16 & 0.18 & 1.2 \\
\hline 000535 & Erzincan & 6.6 & 13 & $13 / 03 / 1992$ & 0.39 & 0.51 & 1.0 \\
\hline 006263 & South Iceland & 6.5 & 7 & $17 / 06 / 2000$ & 0.63 & 0.51 & 1.0 \\
\hline 006334 & South Iceland (aftershock) & 6.4 & 11 & $21 / 06 / 2000$ & 0.42 & 0.72 & 1.2 \\
\hline
\end{tabular}

Table 1. Set of accelerograms selected in order to match the EC8 elastic spectrum for a design ground acceleration on stiff soil equal to $0.35 \mathrm{~g}$. 


\begin{tabular}{|c|c|c|c|c|c|c|c|}
\hline Earthquake code & Earthquake name & Moment magnitude & Epicentral Distance [km] & Date $[\mathrm{dd} / \mathrm{mm} / \mathrm{yy}]$ & PGA_X [g] & PGA_Y [g] & SF [-] \\
\hline 000196 & Montenegro & 6.9 & 25 & $15 / 04 / 1979$ & 0.45 & 0.31 & 1.0 \\
\hline 000199 & Montenegro & 6.9 & 16 & $15 / 04 / 1979$ & 0.38 & 0.36 & 1.0 \\
\hline 000233 & Montenegro (aftershock) & 6.2 & 22 & 24/05/1979 & 0.12 & 0.15 & 1.0 \\
\hline 000288 & Campano Lucano & 6.9 & 43 & $23 / 11 / 1980$ & 0.23 & 0.17 & 1.0 \\
\hline 000535 & Erzincan & 6.6 & 13 & $13 / 03 / 1992$ & 0.39 & 0.51 & 1.0 \\
\hline 006328 & South Iceland (aftershock) & 6.4 & 12 & $21 / 06 / 2000$ & 0.33 & 0.39 & 1.0 \\
\hline 006334 & South Iceland (aftershock) & 6.4 & 11 & $21 / 06 / 2000$ & 0.42 & 0.72 & 1.0 \\
\hline
\end{tabular}

Table 2. Set of accelerograms selected in order to match the EC8 elastic spectrum for a design ground acceleration on stiff soil equal to $0.25 \mathrm{~g}$.

\begin{tabular}{|c|c|c|c|c|c|c|c|}
\hline Earthquake code & Earthquake name & Moment magnitude & Epicentral Distance [km] & Date [dd/mm/yy] & PGA_X [g] & PGA_Y [g] & SF [-] \\
\hline 000228 & Montenegro (aftershock) & 6.2 & 33 & $24 / 05 / 1979$ & 0.20 & 0.27 & 1.0 \\
\hline 000230 & Montenegro (aftershock) & 6.2 & 8 & 24/05/1979 & 0.12 & 0.27 & 1.0 \\
\hline 000288 & Campano Lucano & 6.9 & 43 & $23 / 11 / 1980$ & 0.23 & 0.17 & 1.0 \\
\hline 000535 & Erzincan & 6.6 & 13 & $13 / 03 / 1992$ & 0.39 & 0.51 & 1.0 \\
\hline 001228 & Izmit & 7.6 & 47 & $17 / 08 / 1999$ & 0.24 & 0.14 & 1.0 \\
\hline 001250 & Izmit & 7.6 & 172 & $17 / 08 / 1999$ & 0.09 & 0.10 & 1.0 \\
\hline 005850 & Strofades & 6.6 & 38 & $18 / 11 / 1997$ & 0.13 & 0.12 & 1.0 \\
\hline
\end{tabular}

Table 3. Set of accelerograms selected in order to match the EC8 elastic spectrum for a design ground acceleration on stiff soil equal to $0.15 \mathrm{~g}$. 


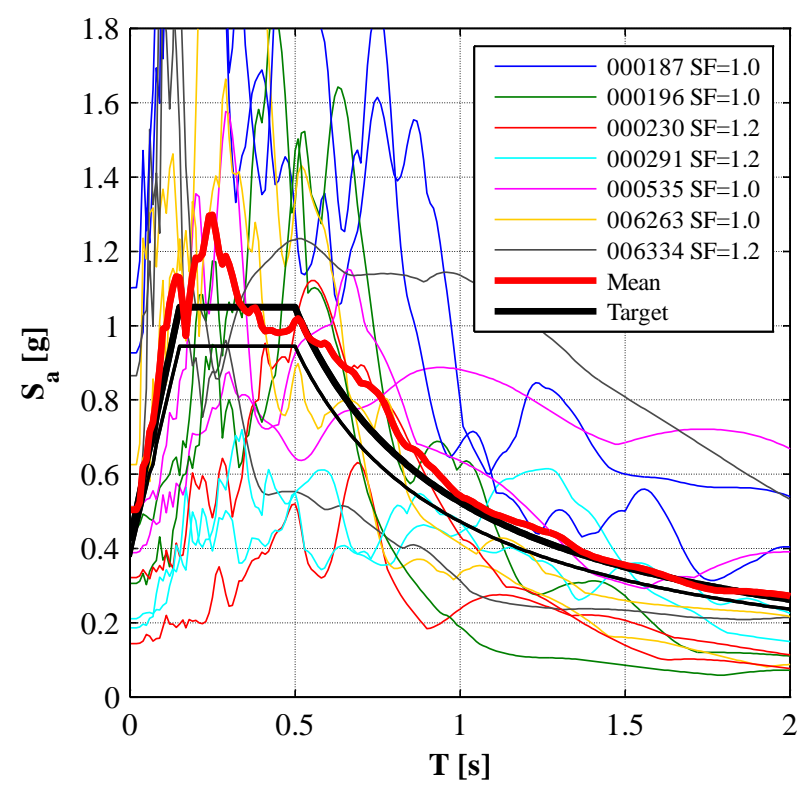

(a)

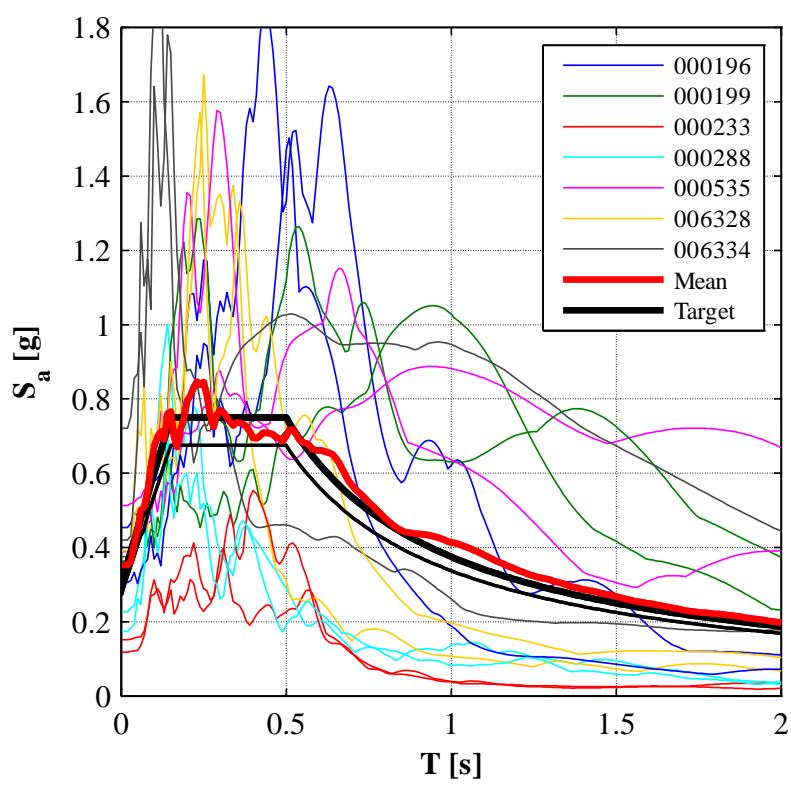

(b)

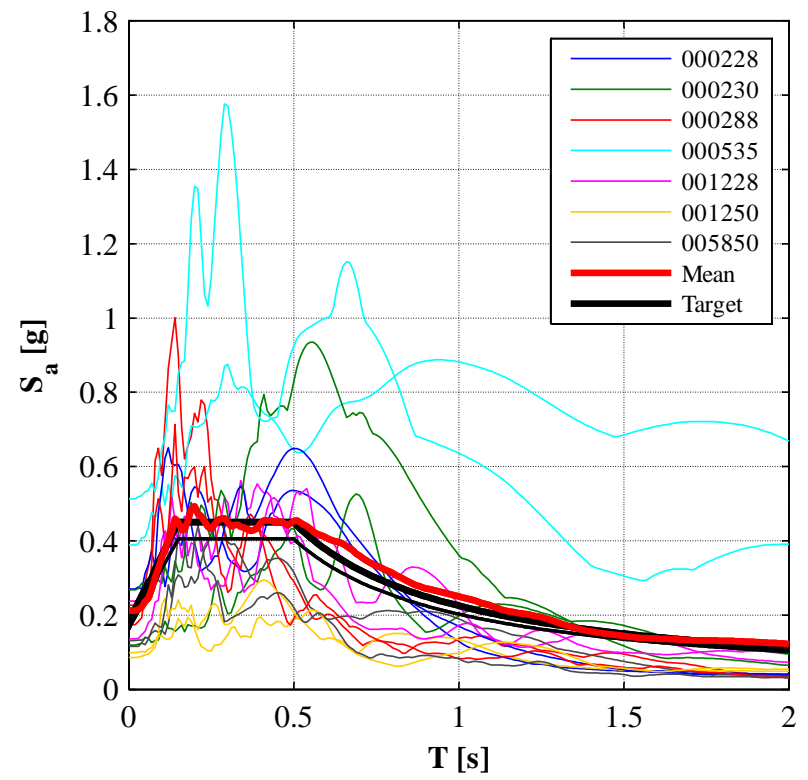

(c)

Figure 2. Comparison of the acceleration response spectra of the selected accelerograms, their mean $5 \%$ damping elastic spectrum (thick red line), EC8 target elastic response spectrum (thick black line) and the $90 \%$ of the target response spectrum (black line) for design peak ground acceleration on stiff soil equal to (a) $0.35 \mathrm{~g}$, (b) $0.25 \mathrm{~g}$ and (c) $0.15 \mathrm{~g}$.

The nonlinear analyses are performed applying, for each earthquake, the two horizontal components simultaneously. The top displacements and rotational ductility demand evaluated at column ends are considered as response parameters. Such a demand is compared to the capacity at the Significant Damage Limit State, which corresponds to the attainment at elements ends of a rotation equal to $3 / 4 \theta_{u}$, mentioned above.

The comparison is also performed at the Near Collapse Limit State; in such a case the demand is evaluated considering the accelerograms amplified by 1.5 and the capacity corresponding to the attainment of the ultimate rotation $\theta_{u}$.

\subsection{Comparison between nonlinear static analyses and nonlinear dynamic analyses}

The results of the nonlinear static analyses are compared with the ones obtained by nonlinear dynamic analyses. The average of the 7 maximum demand values obtained applying the 7 earthquakes is considered to be the result of nonlinear dynamic analysis, following the EC8 rule (Magliulo et al., 2012b). In particular, the ratios (R) between the required rotation and the capacity at the top and at the bottom of each column in the two directions are compared for the three hazard seismic levels; such a comparison is performed considering the maximum ratios 
among all the columns of the building, as well as the average values at each storey level. The evaluations are performed both at the Significant Damage Limit State and at the Near Collapse Limit State. In Figure 3, for sake of brevity, only the maximum ratios $\mathrm{R}$, considering both $\mathrm{X}$ e $\mathrm{Y}$ directions, in the columns at the $1^{\text {st }}$ storey at Significant Damage Limit State are shown; indeed, the damage is concentrated at the first storey, i.e. the maximum $\mathrm{R}$ values are recorded in the column at the $1^{\text {st }}$ storey. For the nonlinear static analysis both the two different distributions of horizontal forces ("uniform" and "modal” pattern) are considered.

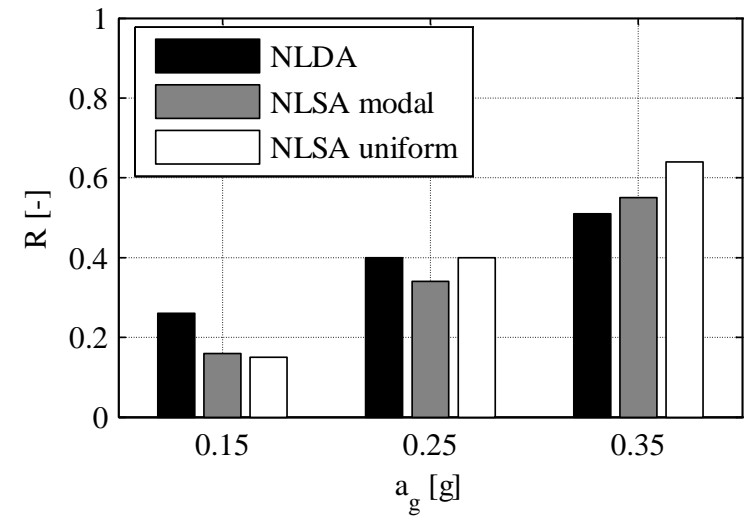

\begin{tabular}{cccc}
\hline $\mathrm{a}_{\mathrm{g}}[\mathrm{g}]$ & $\begin{array}{c}\text { Nonlinear } \\
\text { dynamic } \\
\text { analysis }\end{array}$ & $\begin{array}{c}\text { Pushover } \\
\text { "modal" } \\
\text { pattern }\end{array}$ & $\begin{array}{c}\text { Pushover } \\
\text { "uniform" } \\
\text { pattern }\end{array}$ \\
\hline 0.15 & 0.26 & 0.16 & 0.15 \\
\hline 0.25 & 0.40 & 0.34 & 0.40 \\
\hline 0.35 & 0.51 & 0.55 & 0.64 \\
\hline & &
\end{tabular}

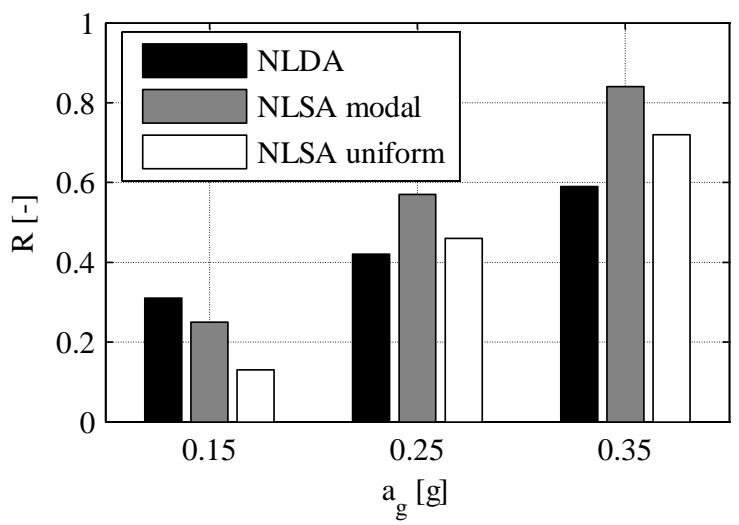

\begin{tabular}{cccc}
\hline $\mathrm{a}_{\mathrm{g}}[\mathrm{g}]$ & $\begin{array}{c}\text { Nonlinear } \\
\text { dynamic } \\
\text { analysis }\end{array}$ & $\begin{array}{c}\text { Pushover } \\
\text { "modal" } \\
\text { pattern }\end{array}$ & $\begin{array}{c}\text { Pushover } \\
\text { "uniform" } \\
\text { pattern }\end{array}$ \\
\hline 0.15 & 0.31 & 0.25 & 0.13 \\
\hline 0.25 & 0.42 & 0.57 & 0.46 \\
\hline 0.35 & 0.59 & 0.84 & 0.72 \\
\hline \multicolumn{4}{c}{ Building no.2 }
\end{tabular}

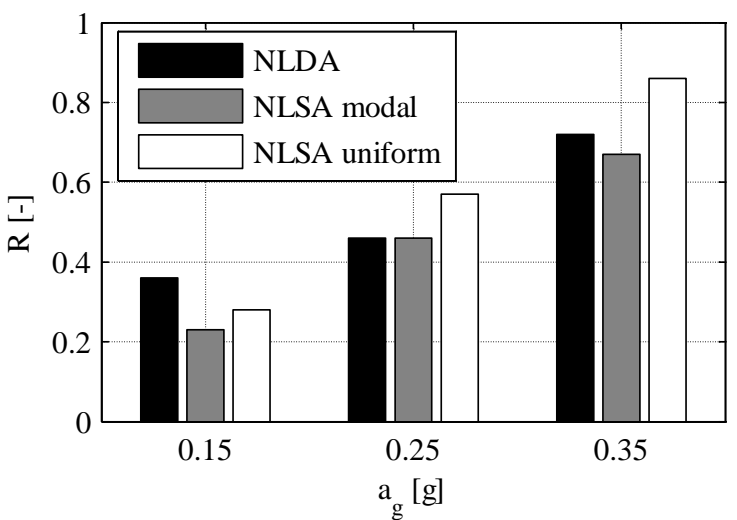

\begin{tabular}{cccc}
\hline $\mathrm{a}_{\mathrm{g}}[\mathrm{g}]$ & $\begin{array}{c}\text { Nonlinear } \\
\text { dynamic } \\
\text { analysis }\end{array}$ & $\begin{array}{c}\text { Pushover } \\
\text { "modal" } \\
\text { pattern }\end{array}$ & $\begin{array}{c}\text { Pushover } \\
\text { "uniform" } \\
\text { pattern }\end{array}$ \\
\hline 0.15 & 0.36 & 0.23 & 0.28 \\
\hline 0.25 & 0.46 & 0.46 & 0.57 \\
\hline 0.35 & 0.72 & 0.67 & 0.86 \\
\hline \multicolumn{4}{r}{ Building no.3 }
\end{tabular}

Figure 3. Comparison between maximum values of the ratio $(\mathrm{R})$ between the required rotation and the capacity in the columns at the $1^{\text {st }}$ storey for nonlinear dynamic analysis (NLDA) and nonlinear static analysis with "modal" load pattern (NLSA modal) and "uniform" load pattern (NLSA uniform) at Significant Damage Limit State for the three considered buildings.

Magliulo et al. (2007) concluded that the safety assessment performed according to the static nonlinear analysis is generally more conservative, i.e. it yields smaller safety factor, with respect to the safety assessment performed according to nonlinear dynamic analysis. Figure 3 shows that such a conclusion, generally valid for new structures designed according to EC8, is not always valid for the analysed buildings. In particular, it is not verified especially for low intensity earthquakes.

As shown in Figure 3, the R values resulting from nonlinear dynamic analyses are smaller than the ones resulting from nonlinear static analysis for low seismic intensity levels. As the seismic hazard level increases, the latter comparison is inverted, i.e. the pushover $\mathrm{R}$ values are larger than the dynamic nonlinear analysis $\mathrm{R}$ values. It 
should be noted that the maximum value between the $\mathrm{R}$ values resulting from modal and uniform load patterns has to be taken into account.

Comparing the $\mathrm{R}$ values among the different structures, the unfavourable behaviour of irregular structures is also confirmed. Indeed, the ratios between the demand and the capacity in buildings no. 2 and no. 3 are larger than the ones recorded in building no. 1 .

The results related to the Near Collapse Limit State (NCLS) follow the same trend shown in Figure 3. However, larger values of the ratio $\mathrm{R}$ are provided, as expected. In fact, the seismic input is $50 \%$ more intense than Significant Damage Limit State (SDLS), while the rotation capacity is 33\% larger than SDLS.

In Figure 4-6, for each floor, the average values of the ratio $\mathrm{R}$ between the required rotation and the capacity, are shown for the three buildings at the Significant Damage Limit State. The ratio $\mathrm{R}$ is computed as the average of the $\mathrm{R}$ values in columns resulting from the $\mathrm{X}$ and $\mathrm{Y}$ orthogonal directions.
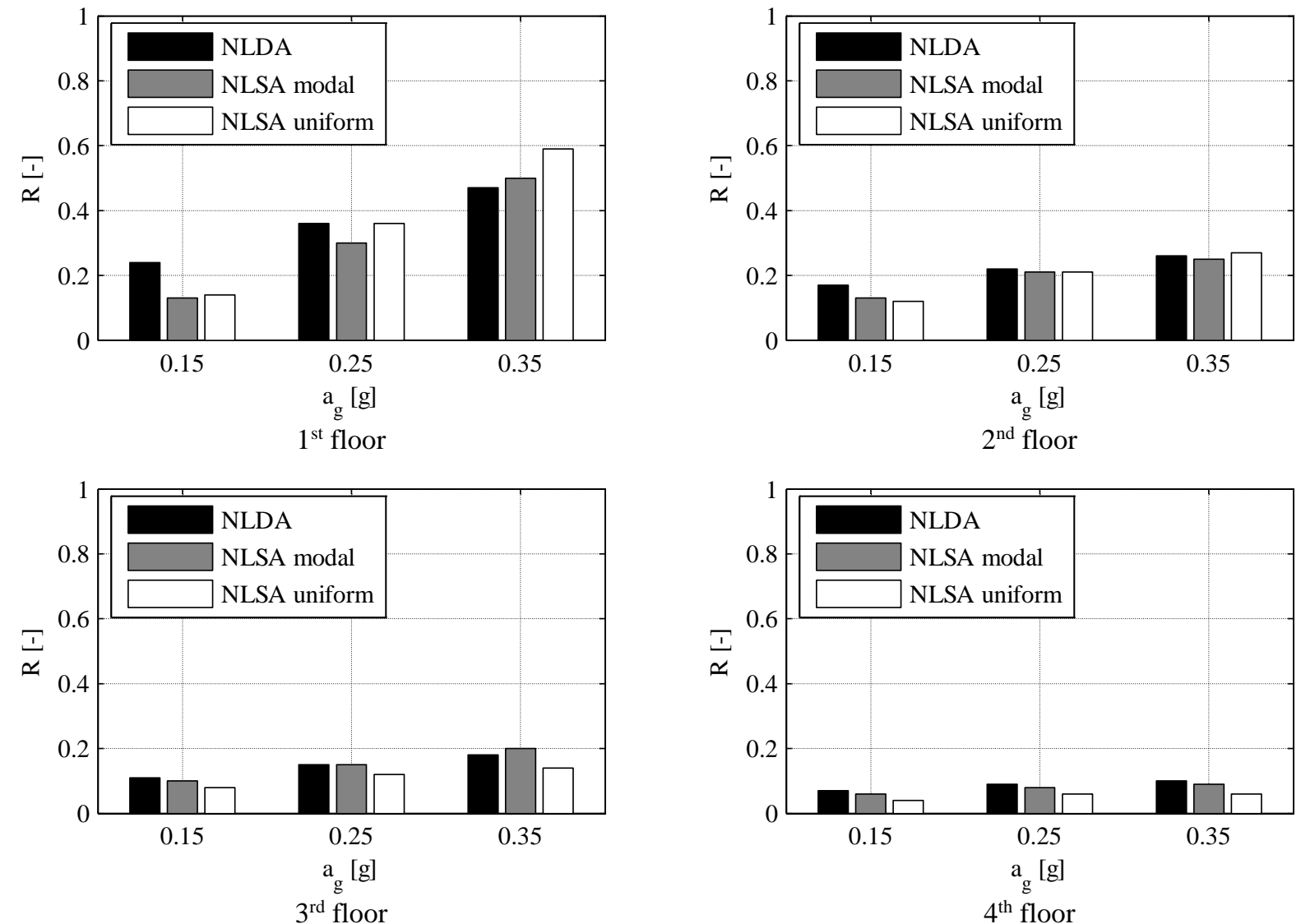

Figure 4. Comparison between average values of the ratios $\mathrm{R}$ between the required rotation and the capacity in the columns at the four storeys for nonlinear dynamic analysis (NLDA) and the ratios R resulting from nonlinear static analysis with "modal” load pattern (NLSA modal) and “uniform” load pattern (NLSA uniform) at Significant Damage Limit State for the building no. 1. 


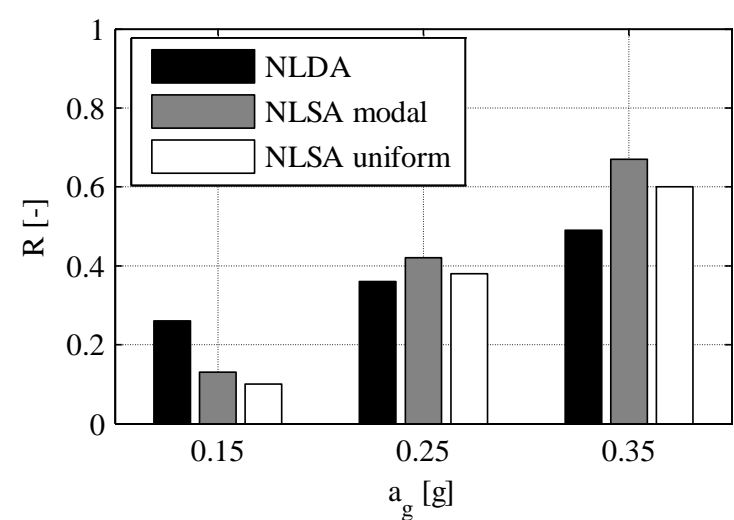

$1^{\text {st }}$ floor

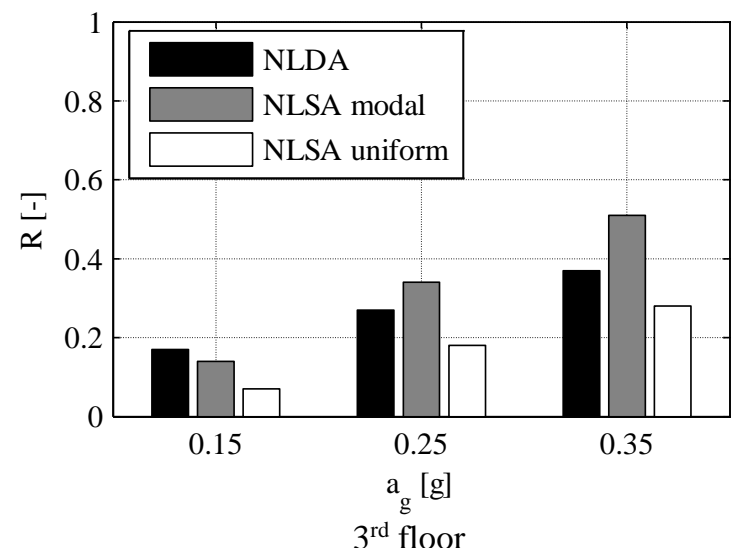

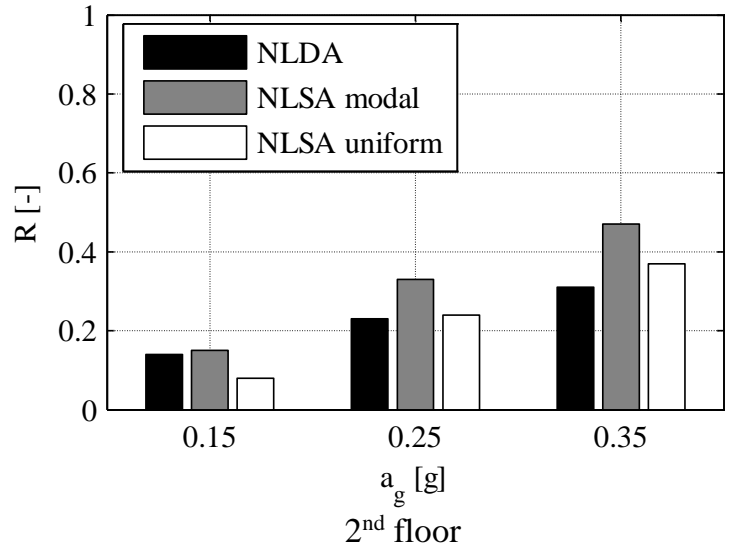

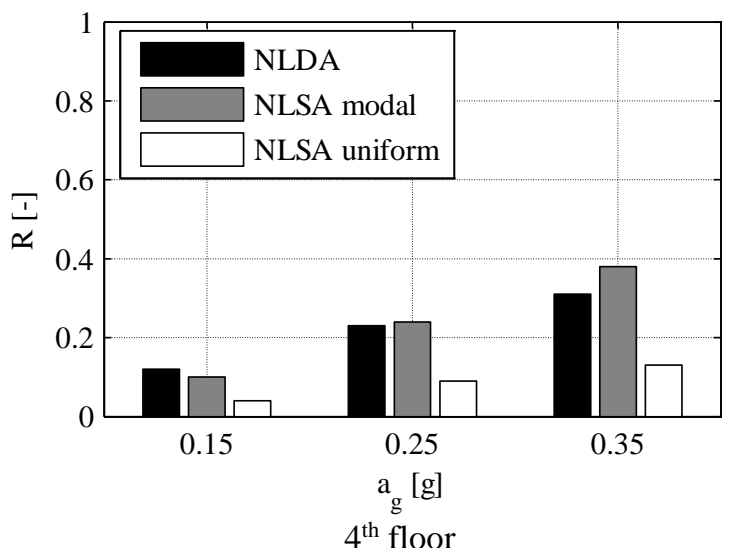

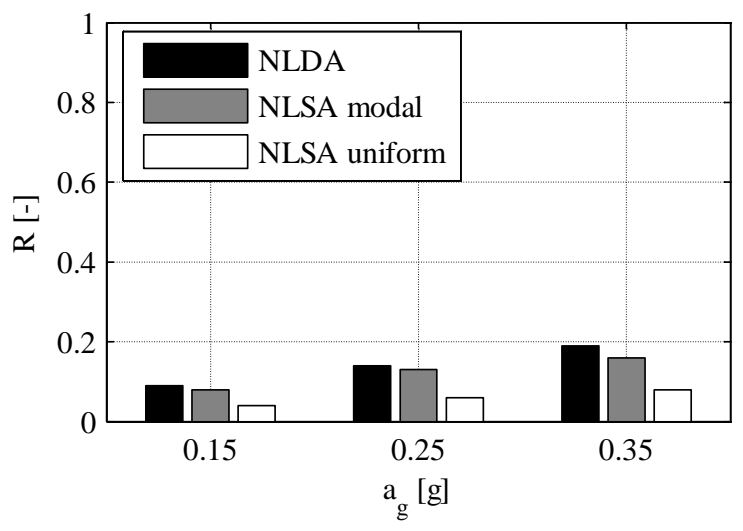

$5^{\text {th }}$ floor

Figure 5. Comparison between average values of the ratios $\mathrm{R}$ between the required rotation and the capacity in the columns at the four storeys for nonlinear dynamic analysis (NLDA) and the ratios R resulting from nonlinear static analysis with "modal” load pattern (NLSA modal) and "uniform” load pattern (NLSA uniform) at Significant Damage Limit State for the building no. 2. 

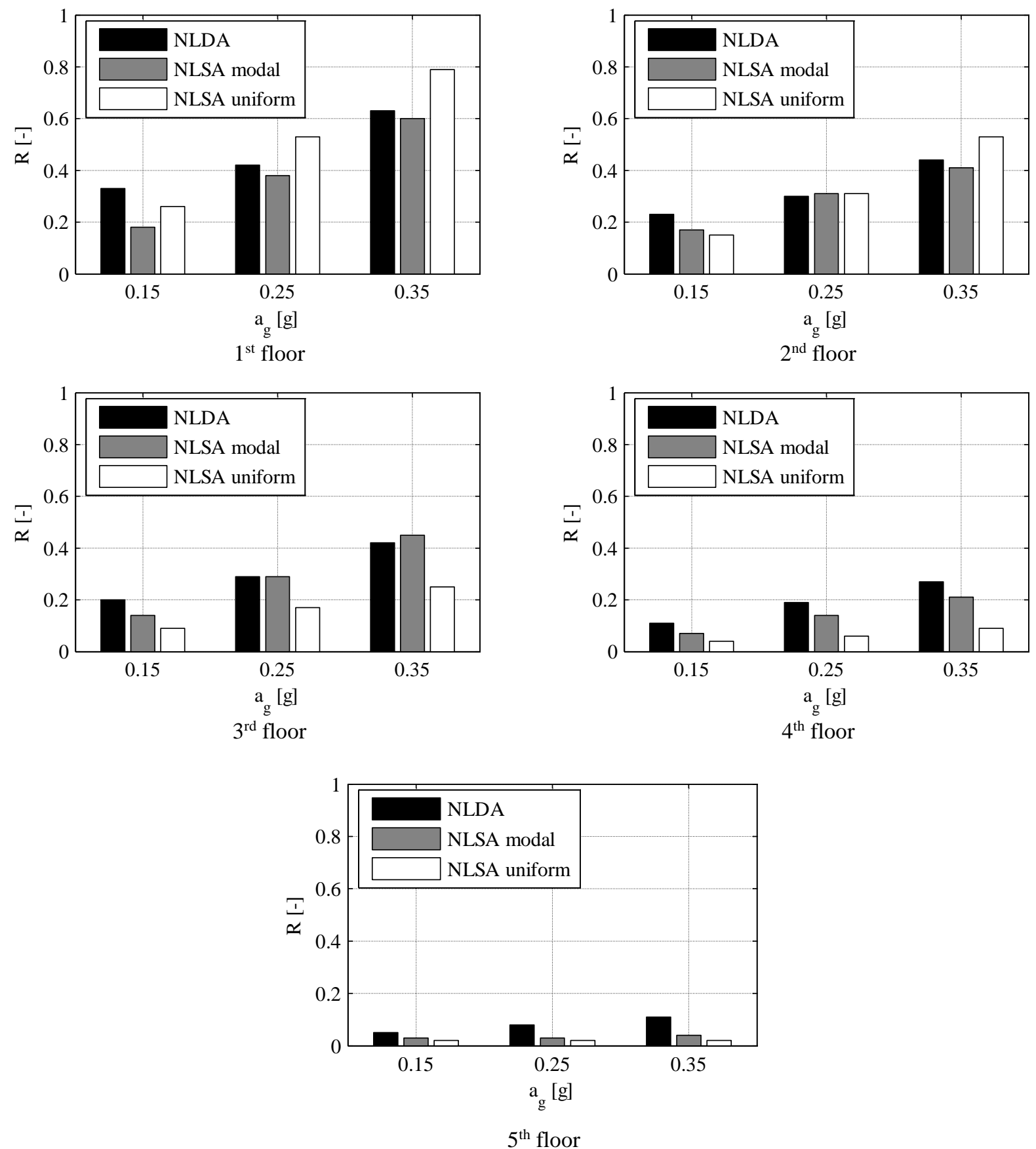

Figure 6. Comparison between average values of the ratios $\mathrm{R}$ between the required rotation and the capacity in the columns at the four storeys for nonlinear dynamic analysis (NLDA) and the ratios R resulting from nonlinear static analysis with "modal” load pattern (NLSA modal) and “uniform” load pattern (NLSA uniform) at Significant Damage Limit State for the building no. 3.

The results in Figure 4-6 show that the pushover analysis performed by the uniform force pattern provides at the bottom floors a larger demand than the one provided by the modal force pattern. They also confirm that nonlinear dynamic analysis gives larger $\mathrm{R}$ values than nonlinear static analysis for low intensity seismic actions.

The average values of $\mathrm{R}$ in building no. 1 (Figure 4) are comparable to the maximum values shown in Figure 3. Instead, for building no. 2 and no. 3, a large discrepancy between average (Figure 5 and Figure 6) and maximum values is provided. This clearly denotes that in irregular structures the demand is concentrated in certain location and the seismic demand is not well divided among the different elements.

The results provided by nonlinear dynamic analyses are larger than the ones provided by pushover analyses at the top floors. The main reason of the underestimation of the demand in pushover analyses is the fact that they do not take into account higher-modes effect, whose influence is significant especially in top floors. The discrepancy between the two analysis methodologies increases with larger seismic intensities. This tendency confirms that the 
more the structure goes in the inelastic range, the greater the influence of higher modes on the seismic response is (Fischinger et al., 2011, Rejec et al., 2012). However, the absolute values of the required rotations are far enough from the capacity; hence, this issue does not compromise the structural assessment for the considered buildings.

\subsection{Influence of the incidence angle on the seismic response}

The building no. 2 is irregular in plan according to the EC8 rules. The influence of the incidence angle on the demand is evaluated on this structure in order to further investigate the seismic performance of this structure that, as known, exhibits an unusual dynamic behaviour. Twelve different earthquake directions are considered, rotating the orthogonal components of the selected accelerograms by 30 degrees for each analysis (from $0^{\circ}$ to $330^{\circ}$ ).

The results in terms of both the top displacements in the two orthogonal directions and the vectorial top displacement (i.e. the Square Root of the Sum of the Squares, namely the SRSS, of the orthogonal displacements) are shown in Figure 7 considering the three selected sets of accelerograms at Significant Damage Limit State. Since the maximum top displacements in the two horizontal directions are not attained at the same time instant, the maximum vectorial top displacement is not directly obtained by composing the maximum $\mathrm{X}$ and $\mathrm{Y}$ displacements.

In Figure 8 the influence of the seismic input angle in terms of the ratio $\mathrm{R}$ between the required rotation and the capacity in column plastic hinges is also shown for the three hazard seismic zones at Significant Damage Limit State.

The incidence angles that induce the largest values of the considered engineering demand parameters are highlighted both in Figure 7 and Figure 8 with a larger marker. 


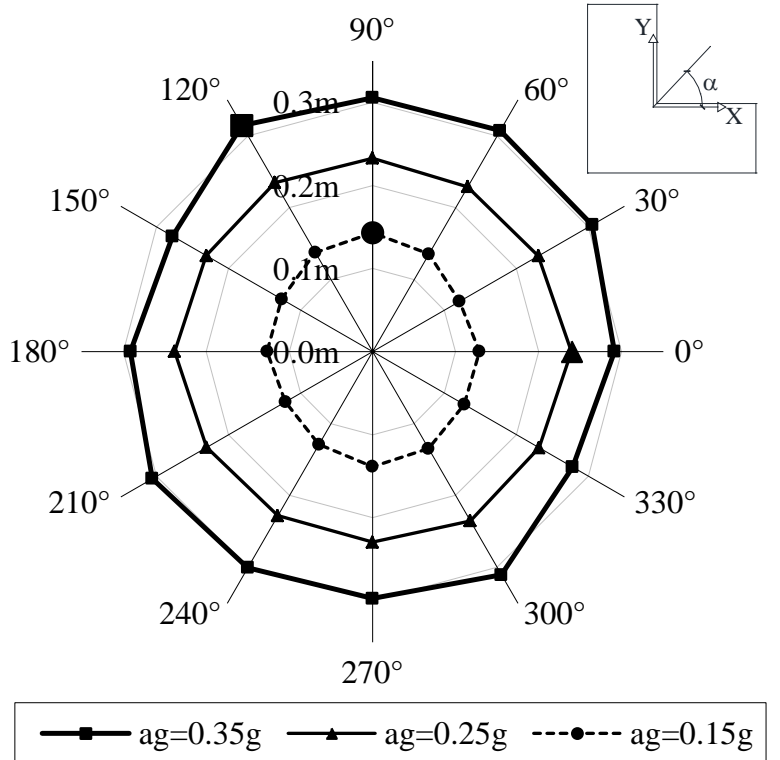

(a)

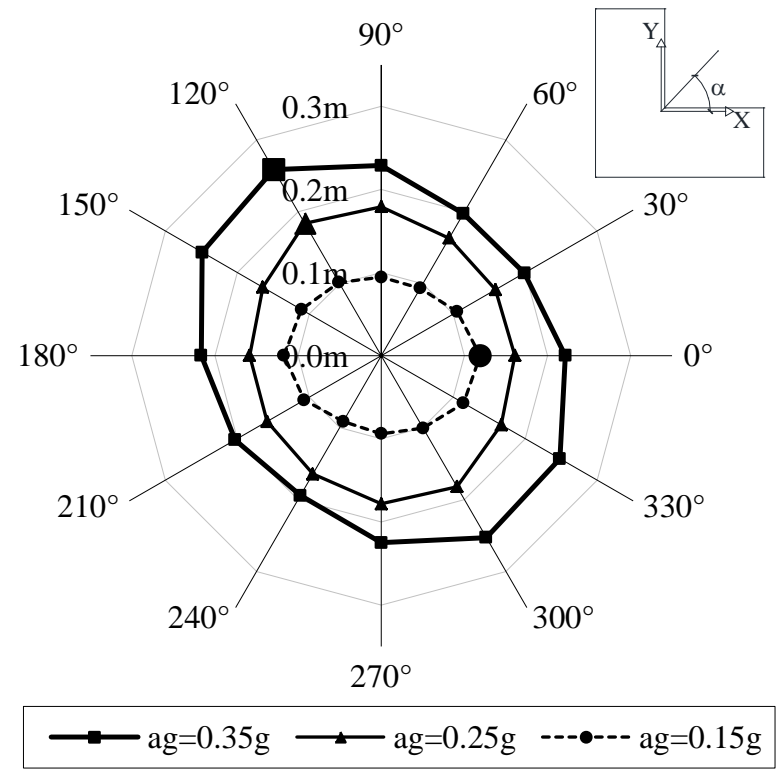

(b)

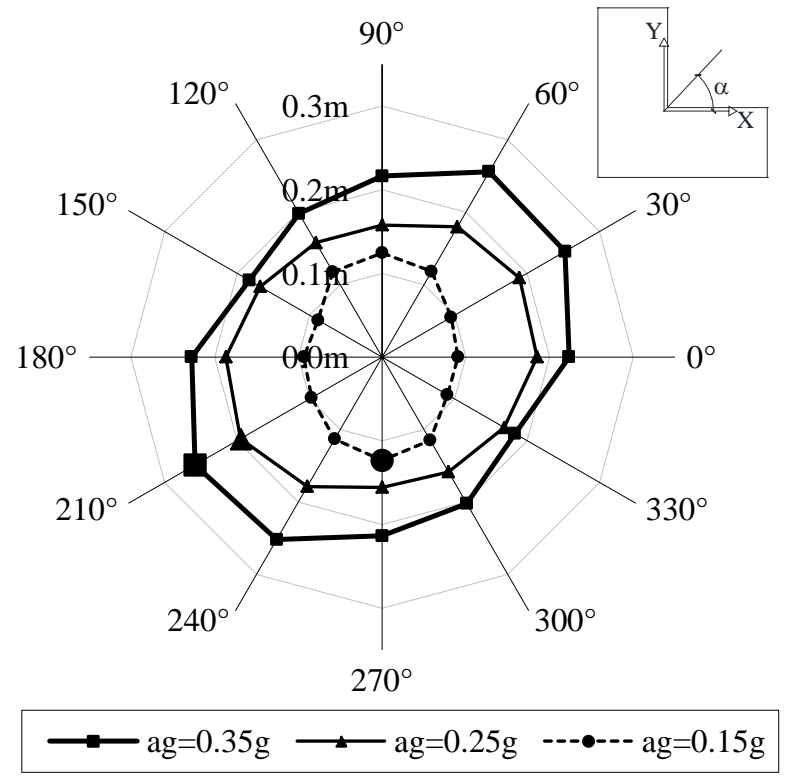

(c)

Figure 7. Influence of the incidence angle $\alpha$ of the seismic input on the response of building no. 2 in terms of (a) top vectorial displacement, (b) X direction top displacement and (c) Y direction top displacement for $0.35 \mathrm{~g}, 0.25 \mathrm{~g}$ and 0.15 g seismic input. 


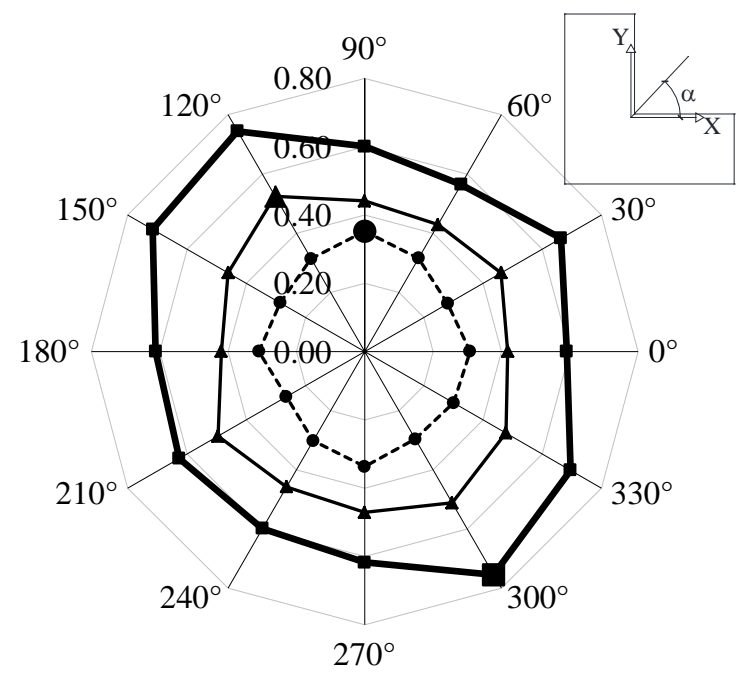

$\longrightarrow \mathrm{ag}=0.35 \mathrm{~g} \longrightarrow \mathrm{ag}=0.25 \mathrm{~g} \cdots-\cdots \cdot-\mathrm{ag}=0.15 \mathrm{~g}$

(a)

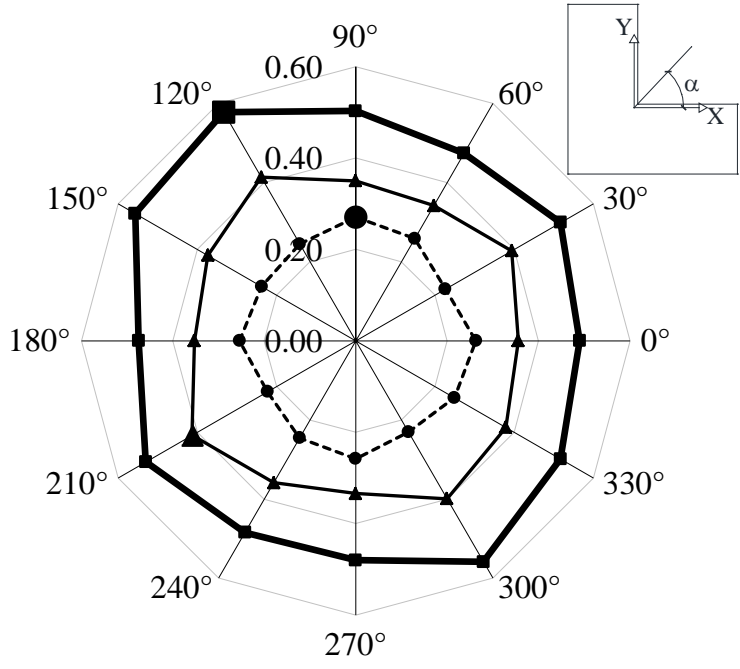

$\longrightarrow \mathrm{ag}=0.35 \mathrm{~g} \longrightarrow \mathrm{ag}=0.25 \mathrm{~g} \cdots-\cdot-\cdots \mathrm{ag}=0.15 \mathrm{~g}$

(b)

Figure 8. Influence of the incidence angle $\alpha$ of the seismic input on the response of building no. 2 in terms of the ratio $\mathrm{R}$ between the required rotation and the capacity considering the (a) maximum attained rotation and (b) the average of the rotations in columns at the first storey.

In Table 4 and Table 5 some of the numerical values plotted in Figure 7 and Figure 8 are shown. The variations of the seismic demand is evaluated with respect to the response obtained applying the input without any rotation. The mean value of the recorded displacement, the standard deviation and the relative coefficient of variation are also evaluated in order to assess the variability of the demand.

\begin{tabular}{|c|c|c|c|c|c|c|c|c|c|c|c|c|}
\hline & \multicolumn{4}{|c|}{$\mathrm{a}_{\mathrm{g}}=0.35 \mathrm{~g}$} & \multicolumn{4}{|c|}{$\mathrm{a}_{\mathrm{g}}=0.25 \mathrm{~g}$} & \multicolumn{4}{|c|}{$a_{g}=0.15 g$} \\
\hline & $\Delta_{\mathrm{x}}$ & var. & $\Delta_{\mathrm{Y}}$ & var. & $\Delta_{\mathrm{X}}$ & var. & $\Delta_{\mathrm{Y}}$ & var. & $\Delta_{\mathrm{X}}$ & var. & $\Delta_{\mathrm{Y}}$ & var. \\
\hline & {$[\mathrm{m}]$} & $\%$ & {$[\mathrm{~m}]$} & $\%$ & {$[\mathrm{~m}]$} & $\%$ & {$[\mathrm{~m}]$} & $\%$ & {$[\mathrm{~m}]$} & $\%$ & {$[\mathrm{~m}]$} & $\%$ \\
\hline $0^{\circ}$ & 0.222 & & 0.223 & & 0.161 & & 0.185 & & 0.119 & & 0.091 & \\
\hline $30^{\circ}$ & 0.199 & -10.2 & 0.252 & 13.0 & 0.159 & -1.2 & 0.189 & 2.3 & 0.106 & -11.4 & 0.095 & 5.0 \\
\hline $60^{\circ}$ & 0.198 & -10.8 & 0.256 & 14.5 & 0.163 & 1.5 & 0.180 & -3.0 & 0.094 & -21.2 & 0.118 & 30.5 \\
\hline $90^{\circ}$ & 0.229 & 3.3 & 0.216 & -3.1 & 0.179 & 11.5 & 0.158 & -14.8 & 0.094 & -20.8 & 0.124 & 37.3 \\
\hline $120^{\circ}$ & 0.259 & 16.7 & 0.198 & -11.2 & 0.184 & 14.4 & 0.158 & -14.7 & 0.102 & -14.5 & 0.118 & 29.7 \\
\hline $150^{\circ}$ & 0.249 & 12.2 & 0.183 & -17.9 & 0.165 & 2.4 & 0.168 & -9.2 & 0.111 & -6.9 & 0.088 & -2.5 \\
\hline $180^{\circ}$ & 0.217 & -2.2 & 0.228 & 2.0 & 0.158 & -1.5 & 0.187 & 0.8 & 0.117 & -1.7 & 0.093 & 3.1 \\
\hline $210^{\circ}$ & 0.203 & -8.3 & 0.258 & 15.7 & 0.159 & -1.3 & 0.196 & 5.6 & 0.107 & -10.2 & 0.097 & 7.5 \\
\hline $240^{\circ}$ & 0.194 & -12.3 & 0.252 & 12.8 & 0.165 & 2.4 & 0.179 & -3.5 & 0.092 & -23.1 & 0.113 & 24.8 \\
\hline $270^{\circ}$ & 0.225 & 1.6 & 0.214 & -4.3 & 0.178 & 11.0 & 0.156 & -16.0 & 0.094 & -21.0 & 0.124 & 36.3 \\
\hline $300^{\circ}$ & 0.253 & 14.0 & 0.202 & -9.5 & 0.182 & 13.3 & 0.158 & -14.4 & 0.101 & -15.4 & 0.115 & 26.8 \\
\hline $330^{\circ}$ & 0.248 & 12.0 & 0.183 & -17.9 & 0.167 & 3.7 & 0.169 & -9.0 & 0.114 & -4.2 & 0.090 & -0.5 \\
\hline MAX & 0.259 & 16.7 & 0.258 & 15.7 & 0.184 & 14.4 & 0.196 & 5.6 & 0.119 & 0.0 & 0.124 & 37.3 \\
\hline$\mu$ & 0.225 & & 0.222 & & 0.168 & & 0.173 & & 0.104 & & 0.106 & \\
\hline$\sigma$ & 0.023 & & 0.028 & & 0.010 & & 0.014 & & 0.010 & & 0.014 & \\
\hline CoV & & 10.3 & & 12.4 & & 5.8 & & 8.2 & & 9.3 & & 13.4 \\
\hline
\end{tabular}

Table 4. Influence of the incidence angle of the seismic input on the response of building no. 2 in terms of $\mathrm{X}$ direction

$\left(\Delta_{\mathrm{X}}\right)$ and $\mathrm{Y}$ direction top displacement $\left(\Delta_{\mathrm{Y}}\right)$ for the three considered seismic intensities. The mean value $(\mu)$ of the recorded displacements, the standard deviation $(\sigma)$ and the relative coefficient of variation $(\mathrm{CoV})$ are also evaluated. 


\begin{tabular}{|c|c|c|c|c|c|c|}
\hline & \multicolumn{2}{|c|}{$\mathrm{a}_{\mathrm{g}}=0.35 \mathrm{~g}$} & \multicolumn{2}{|c|}{$\mathrm{a}_{\mathrm{g}}=0.25 \mathrm{~g}$} & \multicolumn{2}{|c|}{$a_{g}=0.15 g$} \\
\hline & $\mathbf{R}$ & var. & $\mathbf{R}$ & var. & $\mathbf{R}$ & var. \\
\hline & {$[-]$} & $\%$ & {$[-]$} & $\%$ & {$[-]$} & $\%$ \\
\hline $0^{\circ}$ & 0.59 & & 0.42 & & 0.31 & \\
\hline $30^{\circ}$ & 0.66 & 12.2 & 0.46 & 10.1 & 0.28 & -9.0 \\
\hline $60^{\circ}$ & 0.56 & -4.6 & 0.43 & 2.5 & 0.32 & 2.2 \\
\hline $90^{\circ}$ & 0.60 & 1.5 & 0.44 & 5.3 & 0.35 & 14.0 \\
\hline $120^{\circ}$ & 0.74 & 26.0 & 0.53 & 25.4 & 0.31 & 1.5 \\
\hline $150^{\circ}$ & 0.72 & 21.0 & 0.46 & 10.2 & 0.29 & -7.5 \\
\hline $180^{\circ}$ & 0.61 & 3.5 & 0.42 & 0.1 & 0.31 & 0.3 \\
\hline $210^{\circ}$ & 0.63 & 5.9 & 0.50 & 18.4 & 0.26 & -14.1 \\
\hline $240^{\circ}$ & 0.60 & 1.2 & 0.46 & 9.3 & 0.30 & -2.2 \\
\hline $270^{\circ}$ & 0.62 & 4.4 & 0.47 & 12.5 & 0.34 & 9.4 \\
\hline $300^{\circ}$ & 0.75 & 27.6 & 0.51 & 22.2 & 0.30 & -4.0 \\
\hline $330^{\circ}$ & 0.70 & 17.6 & 0.48 & 14.0 & 0.30 & -2.5 \\
\hline MAX & 0.75 & 27.6 & 0.53 & 25.4 & 0.35 & 14.0 \\
\hline$\mu$ & 0.65 & & 0.46 & & 0.31 & \\
\hline$\sigma$ & 0.06 & & 0.03 & & 0.02 & \\
\hline $\mathrm{CoV}$ & & 9.9 & & 7.4 & & 7.7 \\
\hline
\end{tabular}

Table 5. Influence of the incidence angle of the seismic input on the response of building no. 2 in terms of the ratio $\mathrm{R}$ between the required rotation and the capacity considering the maximum rotation attained in columns for the three considered seismic intensities. The mean value $(\mu)$ of the recorded values, the standard deviation $(\sigma)$ and the relative coefficient of variation $(\mathrm{CoV})$ are also evaluated.

In Figure 9, the variation of the ratio $\mathrm{R}$ with the input seismic incidence angle is shown for the different seismic intensities.

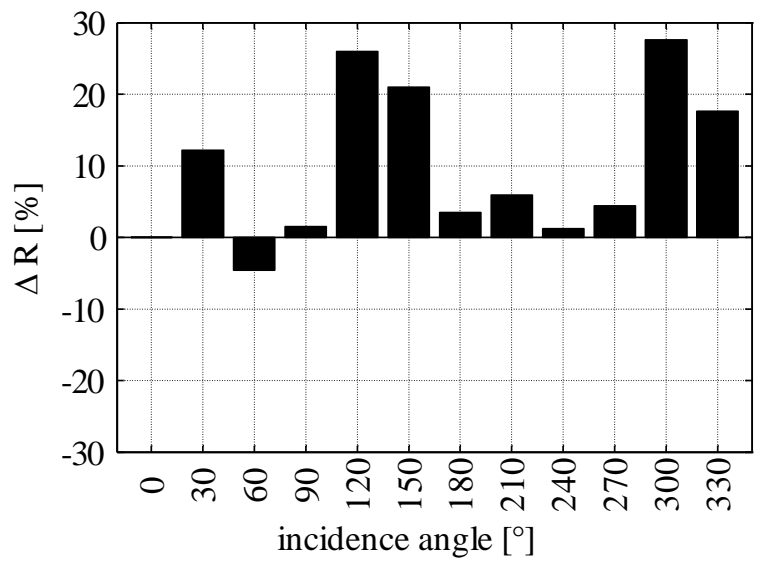

(a)

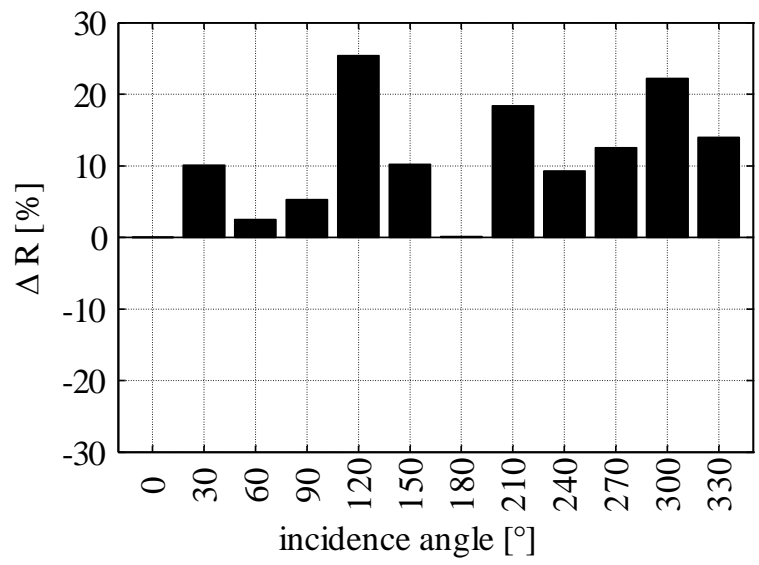

(b)

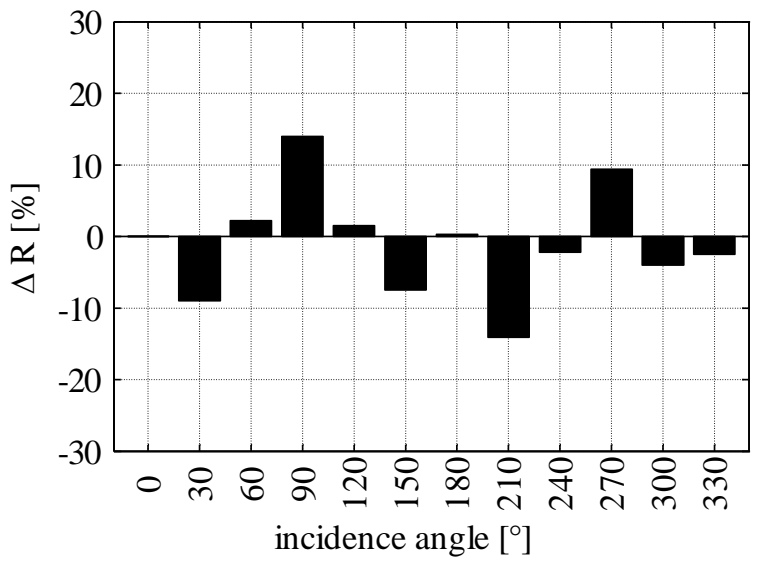

(c)

Figure 9. Influence of the incidence angle of the seismic input on the response of building no. 2 in terms of the variation of the ratio $R(\Delta R)$ between the required rotation and the capacity considering the maximum rotation attained in columns for (a) $\mathrm{ag}_{\mathrm{g}}=0.35 \mathrm{~g}$, (b) $\mathrm{a}_{\mathrm{g}}=0.25 \mathrm{~g}$ and (c) $\mathrm{a}_{\mathrm{g}}=0.15 \mathrm{~g}$.

The following conclusions can be drawn. 
- The incidence angle of the seismic input motion causes a significant variation of the response of RC structures: the variation with respect to the case in which the ground motion is applied without any rotation is about $15 \%$ for the horizontal top displacements. Only in a single case, i.e. Y direction top displacement for $\mathrm{ag}_{\mathrm{g}}=0.15 \mathrm{~g}$, the variation reaches values close to $40 \%$. The top displacement variations, excluding the $\mathrm{Y}$ top displacement case for $\mathrm{a}_{\mathrm{g}}=0.15 \mathrm{~g}$, are in the same range of the outcomes included in Reyes and Kalkan (2012), even if far field records are considered in this study. If the rotations in plastic hinges are analysed, the discrepancy due to a different incidence angle may be up to $30 \%$ (Figure 9). For this reason, the use of a single analysis without considering the uncertainty due to the incidence angle may be questioned.

- The critical incidence angle, i.e. the incidence angle that produces the maximum demand, depends both on the chosen engineering demand parameter, e.g. displacements or plastic hinge rotations, and on the intensity level of the seismic input. This issue clearly denotes the large uncertainty related to the definition of a critical incidence angle.

- The uncertainty in the seismic demand can be represented by the coefficient of variation, i.e. the ratio between the standard deviation and the mean demand value. The coefficient of variation of the required top displacement ranges from 0.06 and 0.13 , while the coefficient of variation of the maximum plastic hinge rotation demand ranges from 0.07 to 0.10 , confirming the non-negligible variation of the seismic demand due to the incidence angle of the seismic input.

An attempt to quantify the uncertainty related to the variability in the incidence angle is also provided. In particular, in Figure 10 the empirical cumulative distribution functions of the three considered demand parameters are shown for the different intensity levels. The empirical distributions are fitted with a lognormal distribution, defined upon the median value of the demand parameter (i.e. $d_{m}$ and $R_{m}$ ) and the standard deviation $\beta$, in order to numerically assess the uncertainty. Indeed, the slope of the lognormal distribution is measured by $\beta$, and reflects the variability (uncertainty) in results (FEMA P695, 2009). 


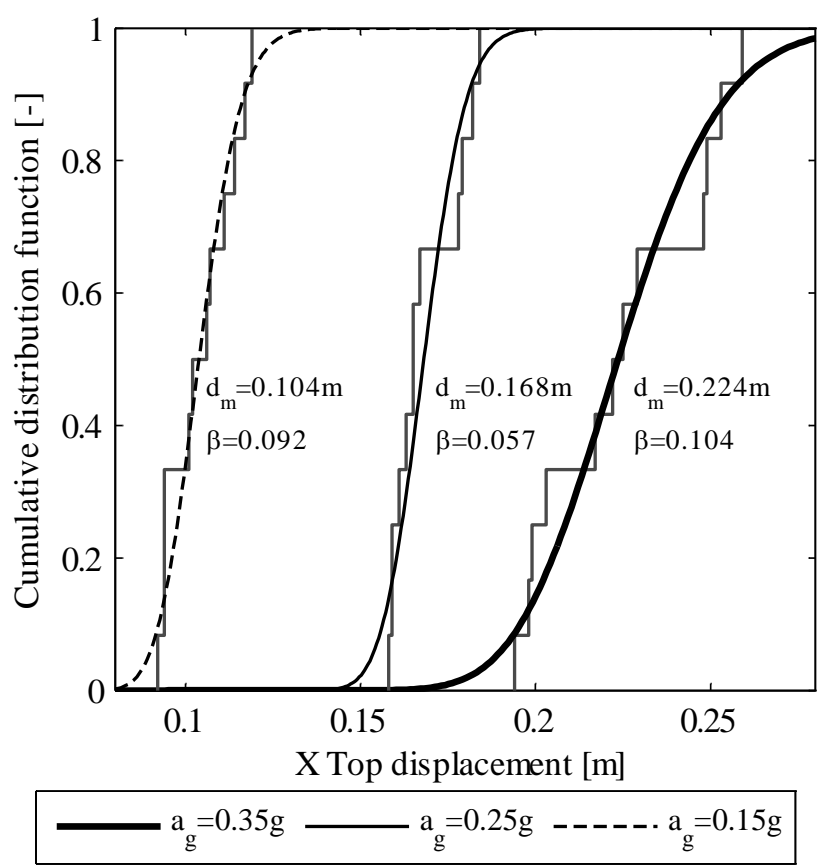

(a)

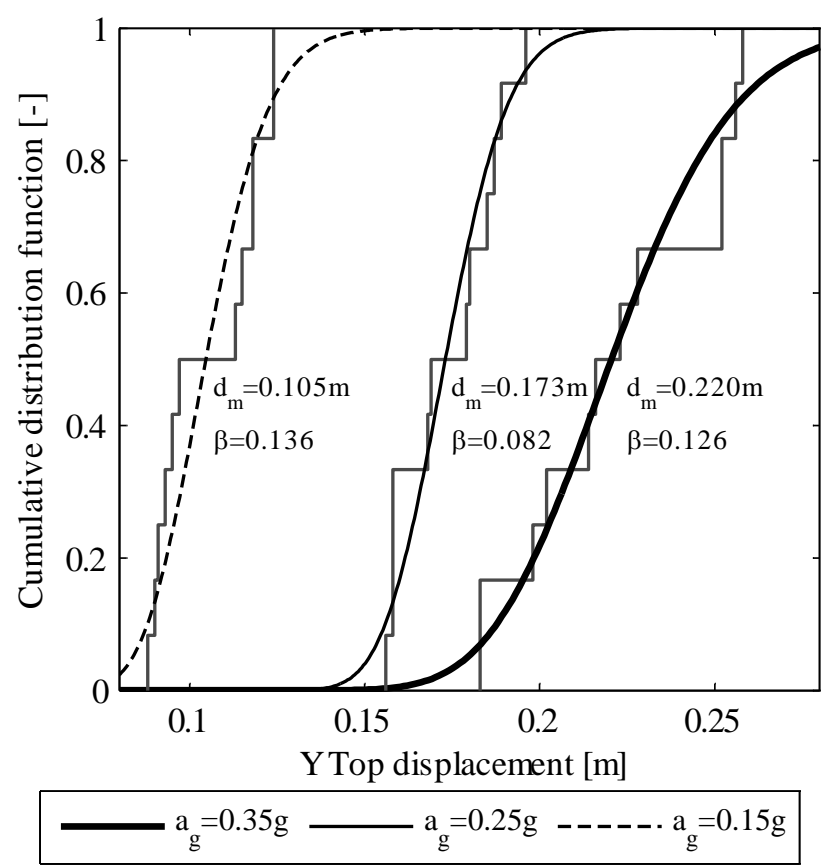

(b)

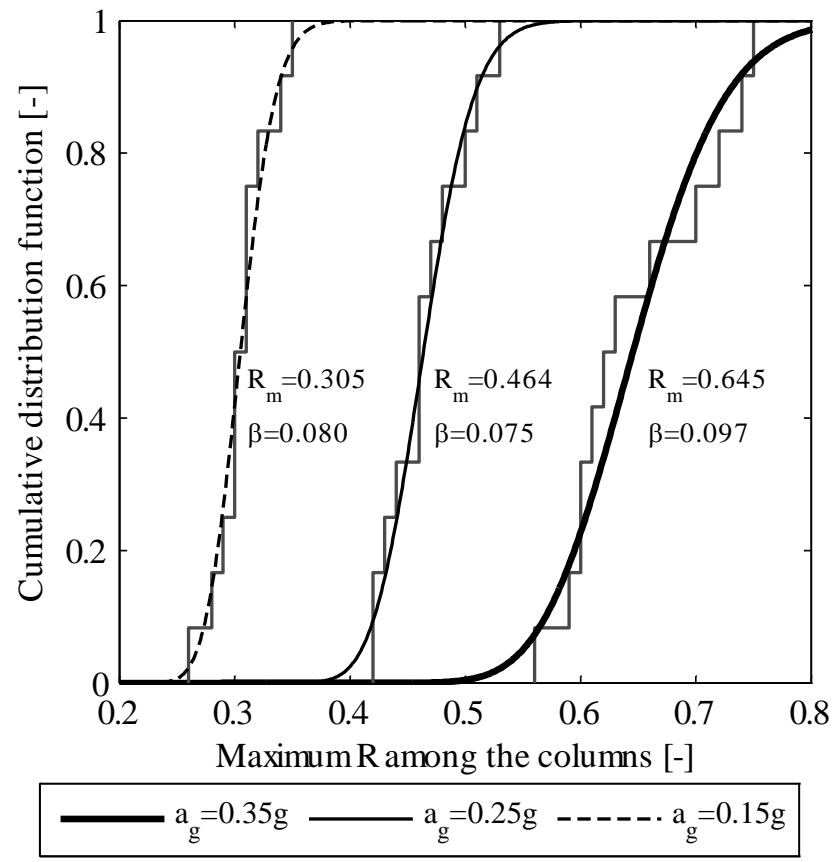

(c)

Figure 10. Empirical cumulative distribution function of the (a) $\mathrm{X}$ and (b) $\mathrm{Y}$ top displacements and (c) the maximum ratio $\mathrm{R}$ among the different columns, fitted with a lognormal distribution, defined upon the median value of the demand parameter (i.e. $d_{m}$ and $R_{m}$ ) and the standard deviation $\beta$.

The uncertainty due to the incidence angle variability for three selected engineering demand parameters is in the range $0.057-0.136$. It could be compared to the $\beta$ values considered by (FEMA P695 (2009)), i.e. the (1) recordto-record uncertainty, (2) design requirements-related uncertainty, (3) test data-related uncertainty and (4) modelling uncertainty. The uncertainty due to the seismic incidence angle is not negligible with respect to the values considered by FEMA P695, which considers $\beta$ ranging from 0.1 to 0.4 for the uncertainties (2), (3) and (4).

\section{CONCLUSIONS}

In the present paper nonlinear methods of analysis (static and dynamic), according to Eurocode 8, are compared considering three different reinforced concrete buildings, representative of typical RC buildings in Italy: a rectangular plan shape, a L plan shape and a rectangular plan shape with a courtyard building. 
Comparing the assessments performed with pushover and the dynamic analyses, it is found that the static nonlinear analysis is more conservative, i.e. it yields smaller safety factors, with respect to nonlinear dynamic analysis for high intensity seismic levels. This conclusion is inverted, i.e. dynamic nonlinear analysis yields lower safety factors, for low intensity seismic levels.

The building no. 2 is irregular in plan according to the EC8 rules. The influence of the incidence angle on the demand is evaluated in order to better explore the seismic performance of this structure that exhibits an unusual dynamic behaviour. Twelve different earthquake directions are considered, rotating the direction of both the orthogonal components of the selected accelerograms by 30 degrees for each analysis (from $0^{\circ}$ to $330^{\circ}$ ).

The results show that the incidence angle of the seismic input motion significantly influences the response of RC structures: the critical seismic angle, i.e. the incidence angle that produces the maximum demand, provides an increase in the demand larger than the $15 \%$ both in displacements and in the ratio $\mathrm{R}$ between the required rotation and the capacity. The underestimation of code compliant dynamic analyses could be up to $37 \%$ if the incidence angle variation is not taken into account. If the rotations in plastic hinges are considered, the discrepancy due to the earthquake incidence angle may be up to $30 \%$; for this reason, such a critical angle should be taken into account in the seismic structural analyses. The critical incidence angle depends both on the engineering demand parameter, e.g. displacements or plastic hinge rotations, and on the intensity of the seismic input. This issue clearly denotes the large uncertainty related to the definition of a critical incidence angle. The coefficient of variation of the required top displacement ranges from 0.06 and 0.13 , while the coefficient of variation of the ratio $\mathrm{R}$ between the required rotation and the capacity ranges from 0.07 to 0.10 .

The performed study has proved the significant influence of the seismic incidence angle on plan-asymmetric structures. Such an influence is not currently included in the building codes; the seismic demand can be significantly underestimated even in case "refined" dynamic nonlinear code-compliant analyses are used. A wide parametric study is required in order to include the influence of the seismic incidence angle in the current building codes.

An attempt to quantify the uncertainty related to the variability in the incidence angle is also provided. In particular, assuming that the seismic demand is lognormally distributed, the uncertainty is quantitatively defined as the lognormal standard deviation $\beta$. The uncertainty due to the incidence angle variability for three selected engineering demand parameters is in the range $0.057-0.136$, and is not negligible with respect to the values considered by FEMA P695.

It should be underlined that the conclusion is related and limited to a single plan asymmetric case study building; a wide parametric study is needed in order to quantify the uncertainty related to the variability in the incidence angle and to achieve more general results. A larger sample of buildings having, for instance, different material strengths and plan-wise configurations should be considered.

\section{REFERENCES}

Ambraseys N, Smit P, Sigbjornsson R, Suhadolc P and Margaris B (2002), Internet-Site for European Strong-Motion Data, European Commission, Research-Directorate General, Environment and Climate Programme.

Athanatopoulou AM (2005), Critical orientation of three correlated seismic components, Engineering Structures, 27(2): 301-312.

Athanatopoulou AM, Makarios T and Anastassiadis K (2006), Earthquake analysis of isotropic asymmetric multistory buildings, The Structural Design of Tall and Special Buildings, 15(4): 417-443.

Bianchi F, Lucchini A, Maddaloni G, Magliulo G, Marino I, Martinelli E, Monti G, Petti L, Saetta A and Spacone E (2007), Seismic vulnerability assessment of existing RC buildings using the new italian seismic code, Proceedings of the Eccomas Thematic Conference on Computational Methods in Structural Dynamics and Earthquake Engineering, Rethymno, Crete, Greece, 13-16 June 2007.

CEN (2004), Eurocode 8: design of structures for earthquake resistance - Part 1: general rules, seismic actions and rules for buildings. EN 1998-1, Brussels, Belgium.

CEN (2005), Eurocode 8: design of structures for earthquake resistance - Part 3: Assessment and retrofitting of buildings. EN 1998-3, Brussels, Belgium.

CSI Computer \& Structures Inc. (2004), SAP2000. Linear and Nonlinear Static and Dynamic Analysis of ThreeDimensional Structures, Computer \& Structures, Inc., Berkeley, California.

De Stefano M and Pintucchi B (2008), A review of research on seismic behaviour of irregular building structures since 2002, Bulletin of Earthquake Engineering, 6(2): 285-308.

Di Sarno L, Elnashai AS and Manfredi G (2011), Assessment of RC columns subjected to horizontal and vertical ground motions recorded during the 2009 L'Aquila (Italy) earthquake, Engineering Structures, 33(5): 1514-1535.

Fajfar P (2000), A Nonlinear Analysis Method for Performance-Based Seismic Design, Earthquake Spectra, 16(3): 573-592.

FEMA P695 (2009), Quantification of Building Seismic Performance Factors, Redwood City, California, US. 
Fischinger M, Ercolino M, Kramar M, Petrone C and Isakovic T (2011), Inelastic seismic shear in multi-storey cantilever columns, Proceedings of the 3rd International Conference on Computational Methods in Structural Dynamics and Earthquake Engineering, COMPDYN 2011, 25-28 May 2011. Corfu, Greece.

Iervolino I, Maddaloni G and Cosenza E (2008), Eurocode 8 compliant real record sets for seismic analysis of structures, Journal of Earthquake Engineering, 12(1): 54-90.

Iervolino I, Galasso C and Cosenza E (2010), REXEL: computer aided record selection for code-based seismic structural analysis, Bulletin of Earthquake Engineering, 8(2): 339-362.

Li KN (1996), Three-dimensional nonlinear dynamic structural analysis computer program package, Technical and Users’ manual. Canny Consultants Pte Ltd.

MacRae G and Mattheis J (2000), Three-Dimensional Steel Building Response to Near-Fault Motions, Journal of Structural Engineering, 126(1): 117-126.

Maddaloni G, Magliulo G, Martinelli E, Monti G, Petti L, Saetta A and Spacone E (2008), Non linear methods for seismic assessment of existing structures: a comparative study on Italian RC buildings, Proceedings of the 14th World Conference on Earthquake Engineering, Beijing, China. 12-17 October 2008.

Maddaloni G, Magliulo G and Cosenza E (2012), Effect of the seismic input on non-linear response of R/C building structures, Advances in Structural Engineering, 15(10): 1861-1877.

Magliulo G, Maddaloni G and Cosenza E (2007), Comparison between non-linear dynamic analysis performed according to EC8 and elastic and non-linear static analyses, Engineering Structures, 29(11): 2893-2900.

Magliulo G and Ramasco R (2007), Seismic response of three-dimensional r/c multi-storey frame building under uniand bi-directional input ground motion, Earthquake Engineering and Structural Dynamics, 36(12): 1641-1657.

Magliulo G, Fabbrocino G and Manfredi G (2008), Seismic assessment of existing precast industrial buildings using static and dynamic nonlinear analyses, Engineering Structures, 30(9): 2580-2588.

Magliulo G, Capozzi V and Ramasco R (2012a), Seismic performance of R/C frames with overstrength discontinuities in elevation, Bulletin of Earthquake Engineering, 10(2): 679-694.

Magliulo G, Maddaloni G and Cosenza E (2012b), Extension of N2 method to plan irregular buildings considering accidental eccentricity, Soil Dynamics and Earthquake Engineering, 43(1): 69-84.

Magliulo G, Petrone C, Capozzi V, Maddaloni G, Lopez P, Talamonti R and Manfredi G (2012c), Shake Table Tests on Infill Plasterboard Partitions, The Open Construction and Building Technology Journal, 6(Suppl 1-M10): 155-163.

Magliulo G, Petrone C, Capozzi V, Maddaloni G, Lopez P and Manfredi G (2013), Seismic performance evaluation of plasterboard partitions via shake table tests, Bulletin of Earthquake Engineering: (in press).

Ordinanza del Presidente del Consiglio dei Ministri n. 3274 del 20/3/2003 (2003), Primi elementi in materia di criteri generali per la classificazione sismica del territorio nazionale e di normative tecniche per le costruzioni in zona sismica (in Italian), G.U. n. 105 dell'8/5/2003.

Rejec K, Isaković T and Fischinger M (2012), Seismic shear force magnification in RC cantilever structural walls, designed according to Eurocode 8, Bulletin of Earthquake Engineering, 10(2): 567-586.

Reyes JC and Kalkan E (2012), Significance of rotating ground motions on nonlinear behavior of symmetric and asymmetric buildings in near fault sites, Proceedings of the 9th International Conference on Urban Earthquake Engineering/ 4th Asia Conference on Earthquake Engineering, Tokyo Institute of Technology, Tokyo, Japan, March 68, 2012.

Rigato AB and Medina RA (2007), Influence of angle of incidence on seismic demands for inelastic single-storey structures subjected to bi-directional ground motions, Engineering Structures, 29(10): 2593-2601.

Roy R and Chakroborty S (2013), Seismic demand of plan-asymmetric structures: a revisit, Earthquake Engineering and Engineering Vibration, 12(1): 99-117. 